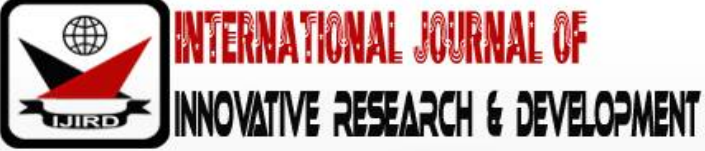

ISSN 2278 - 0211 (Online)

\section{Utilization of Social Media Tools in Students Elections at Masinde Muliro University, Kenya}

Chamegere Mdogo Nashon Elvis
Radio Producer, Department of Journalism and Mass Communication,
Masinde muliro University of Science and Technology, Kakamega, Kenya
Dr. Peres N. Wenje
Dean, Department of Journalism and Mass Communication,
Masinde Muliro University of Science and Technology, Kakamega, Kenya

\begin{abstract}
:
The advent of social media has brought with its new ways of communicating and interacting. Social networking sites have become quite popular in the recent past especially among the youth. They are not only being accessed on computers but also on mobile devices. The capability of social media to allow individuals to share their experiences, opinions and ideas being seen as an enabler for political participation and democracy among youths. The study's specific objectives are, assessing the frequency of use of social media, analyzing the type of social media used and assessing the effectiveness of social media on students' elections. Survey design was used backed by Goffman's framing theory. The study found out that social media is frequently used with WhatsApp the most common followed by Facebook, making WhatsApp an effective way of political communication among students and those who rigorously used social media in elections emerged victors.
\end{abstract}

Keywords: Elections, social media, campaigns, influence, technology

\section{Introduction}

Social media which was once created for personal interaction among people has broadened its scope to include different activities of life (Dutta \& Bhat 2017). Conventional media have taken a centre stage in political communication with Television, radio and others taking the bigger share of political communication but social media is taking over as the driving force for political communication. Most studies in this area have primarily focused on actual contents of communication of social media posts by U.S. politicians (Bronstein, 2013; Gainous \& Wagner, 2014; Golbeck, Grimes, \& Rogers, 2010) with many majoring on small talking points that the politicians talk about. Other studies on social media have been confined to given social media platform with others sticking to the few main accounts of given parties or individuals like twitter handles (Larsson, 2015; Rossi \& Orefice,2016) This study adds to the body of knowledge by accessing the use of multiple social media sites by university students during their election campaigns to ascertain which tool works or suits students campaigns at Masinde Muliro University one of the public Universities in Kenya and why? The study findings could be advanced to a larger political field like the national elections in Kenya and Worldwide.

Human interaction has been transformed and everyone is connected to the other in the vast network generated by the Internet. The Internet has made people global citizens by connecting millions across the World and spreading knowledge. The Internet is part of peoples' lives and its rapid evolution has been spiraled by adoption of social sites that allow citizens to create, distribute and share content in the recent years in what is called social media. This leads to the question, what is Social Media? Jacka and Scott (2011) argue that social media 'can be said to be a set of web-based broadcast technologies that enable the democratization of content, giving people the ability to emerge from consumers of content to publishers'. The Oxford Advanced Learner's Dictionary (2011) defines social media as "websites and applications to communicate with other users or to find people with similar interests to one's own".

For many, social media is Facebook, twitter, WhatsApp, Instagram, Myspace and YouTube. This is because the sites have become common to millions of users. This study borrows the definition from the Attribute-based credential (ABC) technology (2011) a technology website for definitions and explanations and it states, "Social media encompasses digital tools and activities that enable communication and sharing across the net.......",social media is used prolifically by all areas of society: business, politics, media, advertising, police and emergency services. It has also become a key tool for provoking thought, dialogue, and action around particular social issues. The definition fits the bill of analyzing political content on social media.

Social media is currently seen as the driving force Worldwide with its speedy growth turning into a threat to many governments. In the US early 2018 studies indicate that social media landscape is defined by a mix of long-standing trends and newly emerging narratives (Smith \& Anderson 2018) roughly two-thirds of U.S adults (68\%) reported that they are using Facebook and roughly three-quarters of the users access Facebook on daily basis this is the case of South Africa 
which showed that $29 \%$ of the population used Face book with almost a third of the population taking part in conversations and other activities in the same environment showing a shift in the way people interact and socialize (Oresti \& Goldstuck 2018) Upsurge in social media use has been encouraged by the mobile telephones which can easily handle the apps. In Kenya, the Communications Authority of Kenya (CA) sector statistics report for the first quarter of the financial year 2017/ 18 revealed that the number of mobile subscriptions stood at 41.0 million up from 40.2 million reported in the preceding quarter, making a growth of 1.9 percent over the period (State of the Internet in Kenya 2017) The report indicates the most downloaded Apps in Kenya were found to be Uber, Instagram, Facebook, Branch, Face book messenger, True caller, Tala, Facebook Lite, WhatsApp and Opera Mini (State of the Internet in Kenya 2017). Categories of the most visited Websites in Kenya were found to be: internet search engines; sports, gaming and betting websites; sites with adult content, Social Media platforms and entertainment platforms (Akamai, 2017) This has led to set up of laws to govern its usage in several countries Kenya being one of them. The ability to communicate effectively carries a great impact in any company, organization or group's success. This is because it cements team work and collaboration. Effective communication sets room for positive interaction between two or more individuals working together to solve problems and enhance on skills. Political communication calls for selection of an efficient communication channel that will reach all your constituents and the impact it comes with.

Most politicians who have established themselves use internet technologies such as social media to gather intelligence on the voters, organize volunteers, raise funds and research on their opposition (Howard, 2005), social media sites are gaining usage based on their interactive nature, production, consumption and sharing of political content. Mobile technologies including laptops, tablets and the emergence of cheap smart phones allow the masses to be constantly connected, which has had a dramatic impact on how we communicate. Bellingham et al. indicate that $51 \%$ of internet population is using smart phones with majority of them having data subscription as well. According to communications Authority of Kenya (CA) 2017/ 2018 report, the uptake of data services grew significantly in the last quarter of 2017. Total data/ internet subscriptions stood at 33.3 million up from 30.8 million subscriptions as indicated in Table 1 below

\begin{tabular}{|c|c|c|c|c|}
\hline $\begin{array}{c}\text { Internet/ Data } \\
\text { Subscriptions }\end{array}$ & Oct-Dec 2017 & Jul-Sep 2017 & $\begin{array}{c}\text { Quarterly } \\
\text { Variation (\%) }\end{array}$ & Oct-Dec 2016 \\
\hline Mobile Data subscriptions & $33,076,894$ & $30,628,340$ & 8.0 & $26,521,037$ \\
\hline $\begin{array}{c}\text { Terrestrial Wireless Data } \\
\text { Subscriptions }\end{array}$ & 82,362 & 63,749 & 29.2 & 29,724 \\
\hline Satellite Data Subscriptions & 769 & 712 & 8.0 & 584 \\
\hline $\begin{array}{c}\text { Fixed DSL Data } \\
\text { Subscriptions }\end{array}$ & 1,953 & 2,106 & -7.3 & 39,483 \\
\hline $\begin{array}{c}\text { Fixed Fibre Optic Data } \\
\text { Subscriptions }\end{array}$ & 99,643 & 90,548 & 10.0 & 86,139 \\
\hline $\begin{array}{c}\text { Fixed Cable Modem } \\
\text { Subscriptions }\end{array}$ & 96,876 & 99,564 & -2.7 & - \\
\hline $\begin{array}{c}\text { Other Fixed Data } \\
\text { Subscriptions }\end{array}$ & 6,700 & 6,127 & 9.4 & $26,679,222$ \\
\hline Total Internet Subscriptions & $33,365,197$ & $30,891,132$ & 8.0 & \\
\hline
\end{tabular}

Table 1: Data/ Internet Subscriptions

Source: Communication Authority of Kenya, Operators' Returns 2017/ 2018

As illustrated in table 1, the total number of internet subscriptions as at October to December 2017 stood t 33,365, 197 as compared to 30,891,132 as at July to September 2017. This was the electioneering period in Kenya with the August $8^{\text {th }}$ national elections. The same elections so an increase in the number of young voters (European Union report on Kenya 2018) Youths have been termed as the key players of social media technologies and internet usage and can be associated by the findings above. The growth of social media use in Kenya was seen in the Kenyan elections 2017, the number of young voters was massive (European Union report on Kenya, 2018). Political victories today are determined by quantity and quality of information that campaigns can access with regards to their political opponents and constituents (McClurg \& Holbrook 2009). Elections are mainly based on campaigns and how one marshals his campaign team. Several scholars allege to the fact that campaigns matter in elections based on the fact that constituents react to campaign events (Holbrook, 1996; Hillygus, 2005) winners in any election are determined by the number of votes which one gathers and it is purely based on the intensity of campaigns carried out. Social media sites are mostly used by politicians to attract the youths. According to socialbakers (2003), majority of social media users are individuals between the ages of 18-25 that are considered as youths (Socialbakers, 2003). This paper seeks to understand the utilization of social media in students' elections majorly youths based on Masinde Muliro University students in Kakamega County of Kenya.

\section{Objectives}

The study was carried out in Kenya at Masinde Muliro University of Science and technology among undergraduate students to understand how social media networks are utilized in students' elections. The aims of this study were: -

- To assess the frequency of use of social media by students at Masinde Muliro University

- To analyze the type of social media used by students at Masinde Muliro University

- To examine the effectiveness of social media use on students' elections at Masinde Muliro University. 


\subsection{Use of Social Media in Kenya}

Social media platforms such as blogs, twitter and Facebook have registered tremendous growth in Kenya and continued to offer diversity in variety of content available online (Kenya Monitor Report, 2015). Kenyans have taken social media as an effective tool through which they can write on topics of interest as well as exercise their freedom to free speech as guaranteed in the Kenyan constitution 2010. Social media takes a center stage because it offers diversity in terms of topics under discussion and the ease at which they can be discussed. From technology, fashion, health, environment, politics, education, religion, entertainment and leadership, social media builds the users in understanding the trends which is a builder to the use by most youths. Emergence of bloggers in Kenya on variety of topics has led to choice. Nendo Report (2014), which is one of the first reports on social media in Kenya, highlights the rise and growing power of social media influencers as cited by Kenya Monitor report (2015). Blogging is becoming a big business and influential in matters politics. It is a viable business for many young people who are seeking careers in the digital world but the urge to sale political stories and fabricate messages in one or the others favor has tainted it with the fight for likes and subscriptions in the name of seeking for advertisers and propelling fake news.

\section{Theoretical Framew ork}

This paper engages framing theory. As developed by Erving Goffman (1974) and also Gitlin (1980) it is used to explain how media define issues for its customers in terms of both what is significant and how to think about the issues. Any communicative text either informative or persuasive requires narrative structures to organize its discourse. Frames draw attention to some aspects of reality at the expense of others, Several scholars have coined different assumptions and definitions on the theory, one of the most productive researchers in framing theory, the American Political scientist Robert Entman (Entman, 1993) warned of the absence of a unified theory of framing capable of explaining how frames are constructed, how they are manifested in texts and how they influence the minds of the public. (Entman, 1993) posits as "a scattered conceptualization", lacking,' straight forward clear conceptualization that can be generally applicable throughout the social sciences, to political science to linguistics and communication studies. Frames as per the theory are systems of pre-conceived ideas used to organize and interpret new information. In this study, we angle on the definition that framing is how media is able to focus attention on a given event, organize into perspective and with a particular meaning. Frames are crucial devices that help to organize ideas; so as to make sense of important events and to suggest „what is at issue" or stake and," what the event is". "As Robert Entman (1993) states, Framing involves selection and salience. To frame therefore is to select some aspects of a perceived reality and make them more salient in a communicating text, in such a way as to promote a particular problem definition, causal interpretation, moral evaluation, and/or treatment recommendation for the item, framing involves highlighting, emphasizing and making some aspects of the issue more memorable, noticeable and meaningful while marginalizing and discarding others. It is useful in this study as it helps understand the interpretation of issues and information carried on social media by the originators of the content to those who interpret it into meaning. The frames created by social media content authors on matters elections on students' politics carry varied meaning and the consumer also develops different interpretations with reference to the meanings, contexts and intentions contained in it. How social media sites are used to influence the voters is determined by the way the information presented to the audience (the frame) influences the choices they make when they process it.

\section{Methodology}

The research design used in this study was descriptive survey research method. Descriptive survey method information is collected by interviewing respondents or by administering questionnaires to a sample of individuals (Kombo and Tromp, 2014). It can be used when collecting information about people's attitudes, opinions, habits or any of the variety of education or social issues (Orodho \& Kombo, 2002) Descriptive surveys are not only restricted to fact findings, they can also result in formulation of important principles of knowledge and solution to given problems which is the basis of this study. This was used to collect data from Masinde Muliro University Students, aspirants in all contested positions and their campaign team managers. Descriptive method was used in understanding the factors that determine the choice of social media in relation to the other and in getting the opinions of aspirants in students' elections on the type of social media and its use in different positions vied for in students' elections, to achieve this, the researcher administered questionnaires.

\subsection{Target Population}

A study population is an aggregation of elements from which the sample is selected; (Kombo and Tromp, 2006) as cited by (Wachira, 2013) define target population as a group of individual objects or items from which samples are taken for measurement. The population of this study was composed of Masinde Muliro University students chosen because they interact with social media networks on day to day basis. With a population of 15,000 students MMUST was found viable for the study.

\subsubsection{Sampling Techniques}

A sample is a finite part of statistical population whose properties are studied to gain information about the whole (Webster, 1985). Probability sampling approach was employed with stratified sampling which involves dividing the population into homogeneous subgroups and taking a simple random sample in each subgroup to give equal chance to undergraduate students in different years of study. With a population of 17000 students at Masinde Muliro, the study employed a confidence level of $90 \%$ with a Z- score of 1.645 and a margin error of $+/-6 \%$ with a standard deviation of 0.5 . 
Sample Size $=($ Z-score $) 2 *($ standard dev $) 2 /$ margin of error

$(1.645) 2 * .5(.5) /(0.06) 2$

$(2.706025 * 0,25) / 0.0036$

$0.67650625 / 0.0036$

187.918

188

A sample of 200 students was used in the study.

\subsubsection{Data Collection Procedure}

Silverman (2006) and (Kombo \& Tromp, 2006) as cited by (Mugera, 2015) identify questionnaires, personal interview, observation and focus group discussions as instruments of data collection. (Silverman, 2006) on the other hand identifies interviews and observations as key instruments in qualitative research design and adds that questionnaires can be used to inform meaning to a situation under study. For the purpose of this study data was collected using questionnaires

\subsubsection{Questionnaires}

Mugenda (2003), questionnaires are commonly used to obtain important information about a population under study. Data collected under questionnaire is useful in achieving greater validity under qualitative research. The main tool in this study was structured questionnaires because it provides high amounts of data standardization (Mberia, 2009). The questionnaires were administered on a drop and pick later technique.

\subsubsection{Data Collection and Analysis}

The study was done at Masinde Muliro University; the research employed the use of Excel MS for data analysis. Data that was obtained was then analyzed according to thematic concerns.

\subsubsection{Use of Social Media by University Students}

The study focused on the utilization of social media sites by University students and the findings confirm a high student's presence on social media with even Institutions using social media sites to communicate. The findings show that knowledge sharing, collaboration, social interaction and immediate feedback as proved benefits of social media among students in Universities. The participants $45 \%$ female and 55\% male were sampled from the total population with a turnout of $90 \%$ of the respondents of the total 200 questionnaires circulated.

\begin{tabular}{|c|c|c|}
\hline Gender & Number of Respondents & Percentage \\
\hline Male & 99 & $55 \%$ \\
\hline Female & 81 & $45 \%$ \\
\hline
\end{tabular}

Table 2: Percentage of Respondents

Source: Researcher 2018

Table 2 indicates the response in terms of Gender of respondents and the percentages. With a total of 180 questionnaires returned, $55 \%$ of male students' respondent as compared to $45 \%$ female.

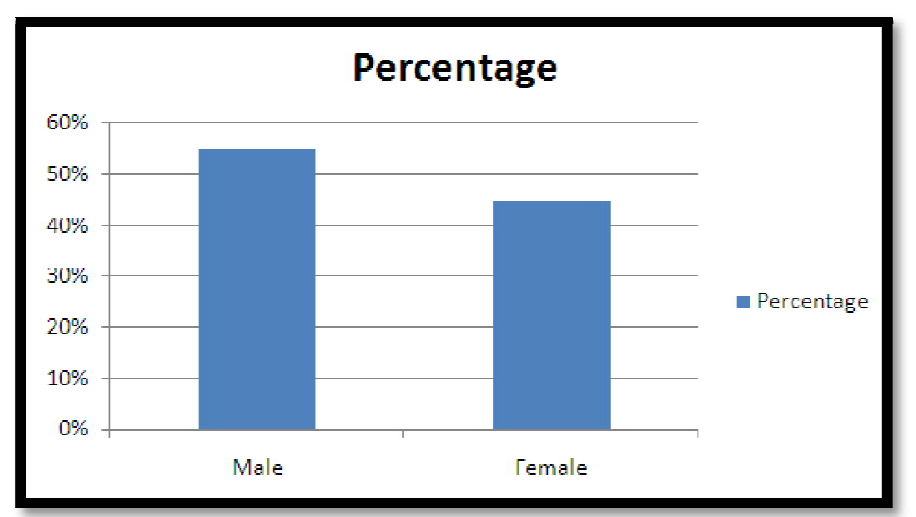

Figure 1: Graph on the Percentage of Respondents

Figure 1 Percentage of respondents' male to Female as per the returned questionnaires

Figure 1, represents the respondents' gender as per the questionnaires with more male filling and returning the questionnaires compared to female University students. As per the findings on those who returned the questionnaires more male than female students were willing to participate in the study as compared to female with reasons as being busy or held up cropping up. The study put to measure the main function of social media sites with news, relationships, education, leisure and privacy. $30 \%$ were of the idea that social media is a good source of news with $20 \%$ settling for education, $30 \%$ for leisure i.e. games and $20 \%$ on issues relationships as indicated in table 3 below 


\begin{tabular}{|c|c|}
\hline Use of Social Media & $\begin{array}{c}\text { Percentage (\%) Among } \\
\text { Respondents }\end{array}$ \\
\hline Source of news & $30 \%$ \\
\hline Education matters & $20 \%$ \\
\hline Leisure and privacy & $30 \%$ \\
\hline Relationships (charting) & $20 \%$ \\
\hline
\end{tabular}

Table 3: Main Function of Social Media Sites among Students

Source: Researcher 2018

As seen in table 3 above social media among youths majorly students are leisure and privacy which majorly means having fan and being a news source. Education matters rank a bit lower on $20 \%$ indicating that the issues shared on social media among the youths carry less educative information and being a comfort zone for leisure the danger of sharing educative content is being rejected or find yourself a lone ranger.

The response is indicated in the bar graph below

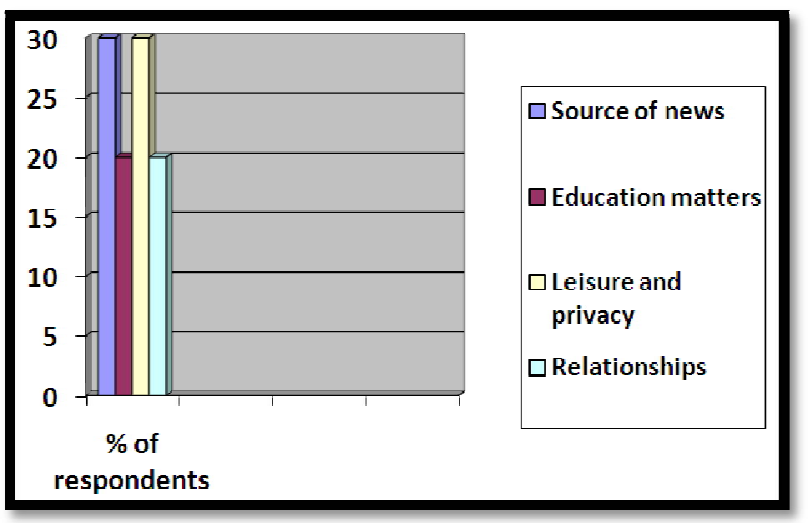

Figure 2: Main Functions of Social Media Sites among Students

As indicated in figure 2, students are more active on social media sites when searching for news stories and during their leisure time. It is indicative of the term "social media" with relationships and Education matters coming last.

Upon interrogation of use of social media sites for political reasons results indicated that individuals were turning to social media networks for information and communication and engage in various content, expression of public issues and topics of interest, whereby $70 \%$ of the respondents were of the idea that social media plays a major role in determining the choice of their leaders while $30 \%$ of the respondents believed that social media does not impact on who they choose as their leader in the university. Respondents opined that social media is an "active" source of voice for political opinion. 58\% belonged to a political or civic advocacy group on WhatsApp and Facebook with WhatsApp leading with a presence of $80 \%$ of the participants actively engaging on political matters and being in "political" groups in support of their candidates. With the changing political landscape and way of campaign among youths, the study found out that political information was sought more from social media sites with those with a higher rating on social media sites emerging victors.

\subsection{Preferred Social Networking Sites}

The study found out that WhatsApp and Facebook take the leading in communication among University students with WhatsApp as the most preferred due to easy exchange of information and sharing content. Most University students have WhatsApp groups based on year of study, regions they come from, courses they partake, areas of residence and political groupings. The limitations of WhatsApp being not everyone can join a group without a link or groups administrator or like as the case with Facebook. Data from questionnaires was used to answer research question, 2) which social media site is preferred by University students.

\begin{tabular}{|c|c|c|}
\hline Preferred Social Media Site & Frequency of Use & Percentage \\
\hline Facebook & 52 & 28.9 \\
\hline Instagram & 10 & 5.6 \\
\hline YouTube & 8 & 4.4 \\
\hline Twitter & 34 & 18.9 \\
\hline Google + & 2 & 1.1 \\
\hline WhatsApp & 70 & 38.9 \\
\hline Others & 4 & 2.2 \\
\hline Total & 180 & 100 \\
\hline
\end{tabular}

Table 4: Preferred Social Media Site by University Students

Source: Researcher (2018) 
Based on the findings in Table 4, the most preferred social media site by University students for political communication is Whats App with the arguments being the site is easily accessible for those with smart phones and can download the App. It was also rated as the easy app to share political information by sharing posters, short video clips and photos. The formation of "community" Whats App groups among students makes it easier to share information and or raise varied strategies for their success. Table 3 findings tally with and reflect the findings by Nendo a Kenyan digital strategy, research and training agency which analyzed the estimated monthly active users per platform based on smartphone penetration as of September 2017 as shown in table 5 below

\begin{tabular}{|c|c|}
\hline Platform & Monthly Users \\
\hline WhatsApp & 12 million \\
\hline Facebook & 7.1 million \\
\hline YouTube & 8 million \\
\hline Instagram & 4 million \\
\hline LinkedIn & 1 million \\
\hline Twitter & 1 million \\
\hline Snapchat & 0.25 million \\
\hline
\end{tabular}

Table 5; Active Users' Platforms as of September 2017

Source: Nendo 2017

Based on the above table WhatsApp is rated the highly used monthly platform as per the report of 2017. Its flexible and easy use features and availability of the internet penetration and mobile subscriptions have contributed to the growth of locally generated content and corresponding among social media communities.

Use of social media sites by University sites at Masinde Muliro University, the preferred Social media sites

\subsection{Effectiveness of using Social Media for Political Communication}

On the question, how effective social media sites are in terms of political campaigns? Respondents stated that social media sites WhatsApp, Facebook, Instagram and YouTube were the sites effective for communication. WhatsApp was rated as the most effective in political communication with $55 \%$ of the respondents stating that it promotes campaigns and is easy to use. WhatsApp is easier to use as the administrator is able to select the people to communicate to and the audience have the liberty to exit the group if it does not suit his/ her political values. WhatsApp was also rated as one would use the available contacts in his/ her phone book to communicate with the masses. Facebook was ranked $2^{\text {nd }}$ with $40 \%$ of the respondents agreeing to the notion that it promotes political communication though with reservations that one needed to have many friends following or likes. Instagram rated at 3\% but it was preferred for accumulating fan base by use of pictures and labeled images to push for one's agenda with YouTube rating at 1\% those who don't believe social media is effective were $1 \%$

\begin{tabular}{|c|c|}
\hline $\begin{array}{c}\text { Type of Social Media Used for Political } \\
\text { Communication }\end{array}$ & $\begin{array}{c}\text { Percentage in Terms of } \\
\text { Ratings for Effectiveness }\end{array}$ \\
\hline WhatsApp & $55 \%$ \\
\hline Facebook & $40 \%$ \\
\hline Instagram & $3 \%$ \\
\hline YouTube & $1 \%$ \\
\hline Do not believe social media is effective & $1 \%$ \\
\hline
\end{tabular}

Table 6: Effectiveness of Using Social Media for Political Communication Source: Researcher 2018

Based on table 6, above the most effective social media among university students for political communication was WhatsApp with 55\% Facebook with $40 \%$ and Instagram with 3\%. WhatsApp was rated highly effective due to its ability to combine both image, video, audio and combination of audio and picture. The use of WhatsApp was also rated to be cheap as long as one is connected to the internet and availability of free Wi-Fi within the university made it even easier to use. Facebook was also rated above other social media sites due to its ability to bring people together with an aspirant required to have many friends or likes to his or her Facebook page. Instagram was used by aspirants to market photos with messages of support or convincing messages for support though its support was rated low.

\section{Conclusion}

The primary goal of this study was to define the utilization of social media with a sense of revealing the most useful social media tool. Study findings revealed that WhatsApp is the preferred social media platform for university undergraduates for political communication and generally online presence. These findings link up with Sanusi, et al (2014) who found out that WhatsApp is widely used as a social media platform among students of polytechnic in Nigeria for academic purpose. WhatsApp is a mobile messaging platform which makes communication easier and faster thereby enhancing effective flow of information and idea sharing among students (Yeboah \& Ewur, 2014). The findings that WhatsApp is the favorite social media platform of university undergraduates is based on the notion that mobile messaging platform has collaborative features which provide university students with the chance to exchange messages, images, 
videos and voice notes to their contacts, political groups or opponents and even study groups. WhatsApp offers university students the opportunity to send messages without limits and create groups who they engage with in forums based on their affiliations and can easily and freely raise support or opposition

\section{Recommendations}

This study found out the great importance of social media in both social and political communication among university students. The introduction of social media in University students' elections and as a campaign tool can be used effectively if regulated to enhance political communication among youths. There's need to formulate a clear communication policy that can streamline the use of social media within higher learning institutions. It recommends that University management should develop short courses that will enhance the use of social media and laws that will manage the use of each media tool used by students. University lecturers can be encouraged to incorporate social media use in learning as a way of encouraging greater students use. With the World evolving, there's need to encourage students to embrace use of technology during elections but done under guidelines and proper regulations.

Law makers should formulate and pass laws that will effectively manage use of social media but not infringe on the constitutional freedoms. There's need to relook at the cybercrime laws passed by the Kenyan law makers as it has been seen to be out to kill use of media and majorly social media.

\section{References}

i. Boyd \& Allison (2007). Networks sites: definition, history, and scholarship. Journal of computer mediated communication

ii. Bronstein, J. (2013). Like me! Analyzing the 2012 presidential candidates' Facebook pages. Online Information Review, 37(2), 173-192.

iii. Entman, R. (1993). Framing: Toward Clarification of a Fractured Paradigm. Journal of Communication, 43. 51-58.

iv. Gainous, J., \& Wagner, K. M. (2014). Tweeting to power: The social media revolution in American politics. New York, NY: Oxford University Press.

v. Gitlin, T. (1980). The whole world is watching: Mass media in the making and unmaking of the New Left. Berkeley, CA: University of California Press.

vi. Goffman, E. (1974). Frame analysis: An essay on the organization of experience. Harvard University press, Cambridge

vii. Golbeck, J., Grimes, J.M. and Rogers, A. (2010). Twitter Use by US Congress. Journal of the American Society for Science and Technology. 61 (8), 612-21.

viii. Holbrook, Thomas M. 1996. Do Campaigns Matter? Thousand Oaks: Sage.

ix. Jacka J M \& Scott PR (2011). Auditing social media - a governance and risk guide. John Wiley and Sons, United States of America

x. Mberia H.K. (2009). Persuasive communication factors that influence university

xi. students in their response to HIV/ AIDS prevention campaign messages. Ph.D. Thesis. Juja. Jomo Kenyatta University of Agriculture and Technology.

xii. Mugenda, O. \& Mugenda, A. (2003). Research Methods: Quantitative and Qualitative Approaches. Nairobi: ACTS Press.

xiii. Mugera R. (2015). Utilization of social media communication in Public Universities. Master's thesis at Jomo Kenyatta University of Agriculture and Technology.

xiv. $\quad$ Nendo (2014). Social media trend report in Kenya

xv. Nirankush, D \& Anil, K. B. Use of Social Media for Political Engagement. Biria Institute of Technology \& Science (BITS)

xvi. Patricios, O. \& Goldstuck, A. (2018). At a glance: The South African Social media landscape.

xvii. Orodho, A. J.\& Kombo, D.K. (2002). Research methods. Nairobi. Kenyatta University, institute of open learning Oxford Dictionary 2011a, Oxford Dictionaries, Oxford, UK.

xviii. Sanusi, R. B., Gambo, I. A. \& Bashir, H. (2014, April). Use of social media among students of

xix. Nigerian polytechnic. Paper presented at International Conference on Communication, Media, Technology and Design, Istanbul, Turkey.

xx. State of Blogging \& Social Media in Kenya, (2015). Report Published by the Bloggers Association of Kenya (BAKE). June 2015

xxi. State of the Internet in Kenya, (2017). Report, Published by the Bloggers Association of Kenya (BAKE). February 2018

xxii. $\quad$ Aaron, S. \& Anderson. M. (2018). Social media use in 2018

xxiii. Social Bakers, (2012). The Recipe for Social Marketing Success. SocialBakers.com.

xxiv. Wachira, MN. (2013). Support services for support remote users in selected public university `libraries in Kenya. Msc Thesis. Pretoria: University of South Africa. 